\title{
Micro cadeias produtivas e a nanoeconomia: repensando o trabalho decente
}

\author{
Peter Kevin Spink
}

Centro de Administração Pública e Governo da Fundação Getúlio Vargas de São Paulo

\begin{abstract}
A expressão "um trabalho decente por um salário decente" fez parte importante das lutas operárias durante grande parte do século XX para um emprego digno, salariado e protegido. Essa mesma expressão foi recentemente assimilada pela Organização Internacional de Trabalho (OIT) como parte central de sua campanha para melhorias nas condições de trabalho. Ninguém disputaria a importância da luta dos trabalhadores em situação de emprego para uma melhoria nas suas condições. Mas, quais são as lutas das pessoas "invisibilizadas" que trabalham no imenso cotidiano das práticas informais, nas tentativas solidárias de criar outras inserções econômicas, de inserir a sua produção em relações econômicas perversas? Se a (grande) maioria das teorias elaboradas no século XX sobre trabalho focaliza como pressuposto básico o universo do trabalho formal, salariado e protegido, quais são os conceitos, práticas e teorias que poderiam apoiar e orientar as ações daquelas pessoas e suas organizações coletivas que buscam assumir o desafio de um outro desenvolvimento a partir das possibilidades do cotidiano e de uma compreensão mais coletiva de dignidade e de cidadania? O que é "trabalho decente" no mundo das micro cadeias produtivas e da nanoeconomia?
\end{abstract}

Palavras-chave: Trabalho decente, Nanoeconomia, Alternativas possíveis.

Micro productive chains and the nanoeconomy: rethinking decent work

The expression "a decent job for a decent pay" was an important part of the trades union struggles during much of the twentieth century for proper working conditions, a fair salary and dignity in the workplace. The same expression (decent work) was recently adopted by the International Labor Organization (ILO) as part of its campaign for improved working conditions. Nobody would dispute the importance of improving working conditions for those in employment. But what are the struggles of those many other "invisible" people who work in the immense day to day of informal practices, in the attempts to create more collective economic alternatives, or to have their products accepted in settings of perverse economic relations? If the great majority of theories of work elaborated in the twentieth century focus, as a basic assumption, formal salaried employment, what are the concepts, practices and theories that could support and give direction to the actions of those people and their collective organizations who seek another possibility of development using everyday opportunities and a more collective understanding of citizenship? What is "decent work" in the world of micro-productive chains and the nanoeconomy?

Keywords: Decent work, Nanoeconomy, Possible alternatives.

\section{Introdução}

\begin{abstract}
A expressão "um trabalho decente por um salário decente" fez parte das lutas e conversas operárias durante grande parte do século XX. Simbolizava uma inserção justa em um mundo caracterizado pelo emprego salariado e protegido. Foi o foco implícito e explícito da maioria das principais teorias da psicologia organizacional e do trabalho nos países centrais. Questões sobre salário, condições de trabalho, benefícios e organização do trabalho sempre tiveram como pano de fundo o pressuposto moral de uma relação de trabalho digna e, se não igual, pelo menos justa. No relatório da Organização Internacional de Trabalho (OIT) sobre a implementação das metas de desenvolvimento social da declaração de Copenhagen (1995) está registrado que:
\end{abstract}

O trabalho decente é o primeiro passo para sair da pobreza e também para uma maior integração social (...) O programa da OIT sobre trabalho decente busca atingir quatro 
objetivos: a criação de emprego, a promoção dos direitos humanos no trabalho, a melhoria da seguridade social, a promoção do diálogo social (OIT, 2000, p. 12). ${ }^{1}$

Na posição da OIT, identifica-se a importância de um trabalho que é produtivo e seguro, em que há respeito em relação aos direitos do trabalho, renda adequada, proteção e diálogo social, liberdade sindical, negociação coletiva e participação ${ }^{2}$. Entretanto, também no relatório da OIT, reconhece-se o papel cada vez mais importante do universo dos pequenos empreendimentos, das atividades do trabalho por conta própria e dos programas intensivos em geração de empregos, como também da presença, especialmente nos países em desenvolvimento, da economia informal, cujas atividades estão frequentemente fora do escopo da proteção social e laboral.

Em grande parte, por causa de sua formação e orientação ao longo de mais de quase 90 $\operatorname{anos}^{3}$, a OIT tenta, por meio de seu relatório, reconciliar uma contradição cada vez mais marcante entre o desejo do trabalho regularizado e a precariedade do trabalho encontrado, argumentando na direção de buscar-se uma atitude mais construtiva em relação à economia informal. Infelizmente, parece que essa reconciliação tem se tornado quase impossível. Os dados disponíveis para a América Latina (OIT, 2001) demonstram que a informalidade aumentou significativamente nos últimos dez anos e, apesar de uma melhoria recente, é difícil imaginar uma situação na qual a maioria das pessoas estará em empregos formais e protegidos ou que haverá qualquer aproximação ao pleno emprego (Antunes, 1999; Esteves, 2002). Ao contrário, em termos do mercado empresarial em geral, as pessoas, em sua maioria, são "sobrantes" - para utilizar a expressão que Robert Castel (1997) cunhou para a situação europeia, mas que também se faz presente em muitos países do "sul global" (Kabeer \& Cook, 2008).

Esse cenário coloca a psicologia do trabalho, enquanto campo de conhecimento, em uma posição difícil. Primeiro, porque grande parte de suas teorias foi - como não poderia deixar de ser - construída sob a mesma perspectiva hegemônica que influenciou a OIT: a do trabalho assalariado e sindicalizado em uma empresa de porte suficiente para fiscalizar condições e assegurar direitos previdenciários. Como Bill Buenar Puplampu (2003) comentou recentemente, a psicologia do trabalho nos países centrais fixou-se somente nas profissões, nos gestores e nos grupos de trabalhadores mais fáceis de definir, incluindo, até certo ponto, os desempregados que estão à espera de empregos desse tipo. Ignorou o número considerável de trabalhadores no mundo inteiro que são motoristas de táxi, salva-vidas, motoristas de ônibus, garis, atores de teatro, agricultores e vendedores ambulantes, dentre outros. De uma análise dos 183 estudos empíricos publicados na revista britânica Journal of Occupational Psychology entre 1990 e 2000, Puplampu (2003) anotou que somente sete faziam menção a, ou focalizavam, grupos menos tradicionais, e esses não constituíam exatamente profissões "estranhas": motoristas de ônibus (três estudos), pessoal de cabine de voo, mulheres empreendedoras, trabalhadores manuais e ajudantes gerais de hospitais. Ou seja, não somente as teorias, os conceitos e os instrumentos são construídos para e a partir da situação estável do emprego salariado dentro de uma organização burocrática, mas a variedade de situações estudadas é também limitada. Dados similares emergem ao analisar o tradicionalíssimo Annual Review of Psychology, cujos artigos de revisão para o campo de psicologia organizacional e do trabalho destacaram, nas 50 edições entre 1950 e 2000, quase que exclusivamente estudos feitos em grandes organizações privadas, públicas ou militares.

\footnotetext{
1 Tradução do autor.

2 "Decent work means productive work in which rights are protected, which generates an adequate income, with adequate social protection" (Somavia, 1999).

3 Fundando em 1919, entrou no sistema das Nações Unidas em 1946 e continua como a única agência tripartite, reunindo representantes de governos, empregadores e trabalhadores.
} 
Como resultado, a psicologia do trabalho, de maneira geral, não se equipou com as técnicas analíticas e conceituais que lhe permitiriam agir criativamente em uma situação em que o normal virou marginal e o marginal virou normal. Diante dos desafios atuais das múltiplas rupturas nas práticas de emprego e renda, com as fragmentações dos mercados e a busca por maneiras de "se virar", o "kit de ferramentas universais" da psicologia do trabalho tornou-se não somente limitado, mas, em grande parte, obsoleto.

\section{Uma catástrofe em câmara lenta}

Pelos dados do IBGE (2004), estima-se que, de todas as pessoas economicamente ativas no Brasil, somente $42 \%$ estão em situação de trabalho assalariado com emprego protegido, incluindo aqui os servidores públicos. Vinte e cinco por cento trabalham sem carteira, outros $23 \%$ trabalham por conta própria e $10 \%$ são desempregados. Os rendimentos das pessoas sem carteira profissional e das pessoas que trabalham por conta própria são, em média, 70\% e 45\%, respectivamente, dos valores que recebem as pessoas assalariadas.

A informalidade, de acordo com os dados do IPEA (2006), já caracteriza mais da metade da força de trabalho, variando de $40 \%$ na indústria, $52 \%$ e $53 \%$ no setor de serviços e comércio, até $78 \%$ na agricultura. São dados que, de acordo com o estudo, refletem o "funcionamento deficiente do mercado de trabalho". Revelam também uma desigualdade total entre oportunidades de inserção econômica e níveis de renda possíveis, aliada a outras desigualdades de gênero e raça.

Estima-se que algo em torno de nove em cada dez empregos formais criados são de nível de rendimento de até dois salários mínimos e com muito pouca exigência de escolaridade. Estudos da Unicamp (CESIT, 2006) apontam para uma expansão de 127\% nos postos terceirizados entre 1995 e 2005. No país, avalia-se que cerca de 63\% dos jovens entre 15 e 24 anos que conseguem entrar no mercado de trabalho têm uma inserção informal (Abramo \& Branco, 2005). No mais recente estudo do IPEA (2008), o Brasil lidera o ranking de maior proporção de jovens entre os desempregados de dez países. Jovens entre 15 e 24 anos representam 46,6\% dos desempregados brasileiros, em contraste com 39\% na Argentina e na Grã Bretanha, 25\% na Itália e na Espanha e 16\% na Alemanha.

Ainda é cedo para saber com clareza como se comportarão esses indicadores após os eventos econômicos mundiais do segundo semestre de 2008, mas tudo indica que a fragilização aumentará consideravelmente, como também o impacto nos grupos já fragilizados e vulneráveis.

\section{Sinais de uma nova psicologia social do trabalho}

Foi comum em vários momentos da história do desenvolvimento acadêmico e intelectual brasileiro e entre pesquisadores progressistas uma determinada cultura de intolerância contra as teorias importadas do hemisfério norte, reflexo talvez de uma contrareação a uma hegemonia política e econômica bastante agressiva. Na situação atual, seria muito útil ter com quem dialogar neste momento. Infelizmente, as revisões da literatura conforme comentado acima - sugerem que estamos, para todos os efeitos, sozinhos. Mas há, 
sem dúvida, outros colegas no terceiro mundo com as mesmas reflexões e teremos de nos esforçar para encontrá-los .

Felizmente, ao contrário da situação dos países centrais, há na psicologia brasileira, tanto na organizacional quanto na do trabalho, uma preocupação crescente com a elaboração de estudos sobre as caóticas relações entre remuneração, renda, trabalho, emprego e atividade, identificada, em parte, com os esforços programáticos dos Cadernos de Psicologia Social do Trabalho.

A tarefa é clara, mas exigente: compreender o dia-a-dia das pessoas "invisibilizadas", que trabalham no imenso cotidiano das micro cadeias produtivas e das práticas informais na nanoeconomia (Spink, 2007), sendo afogadas por relações econômicas perversas, e acompanhar as lutas das tentativas solidárias de criar outras inserções econômicas; ademais, questionar sobre quais seriam os conceitos, as práticas e as teorias que poderiam apoiar e orientar as ações daquelas pessoas e suas organizações coletivas, que buscam assumir o desafio de um outro desenvolvimento cotidiano e uma compreensão mais coletiva de dignidade e de cidadania; e, finalmente, responder à pergunta sobre o trabalho decente, não com base em uma versão idealizada de trabalho assalariado e estável, mas a partir daquilo que temos - queiramos ou não.

\section{Fragmentos de alternativas possíveis: orientação metodológica}

De maneira progressiva na psicologia, renomados pesquisadores e presidentes de associações científicas têm ponderado sobre o papel potencialmente negativo que a preocupação exagerada com o método desempenhou na pouca contribuição da psicologia às questões práticas da humanidade. Não há dúvida de que o método é uma característica de qualquer campo disciplinar que se insere na modernidade, permitindo que as pessoas possam conversar sobre os caminhos pelos quais chegaram a certos postulados, sugestões ou até convicções. O problema emerge quando a conversa vira obrigação, quando o conteúdo da conversa vira tema de censura e o método, em vez de descrição, torna-se especificação.

Em uma série de textos recentes, argumentamos a favor de uma abordagem mais minimalista em termos de método (Spink, 2003, 2007b, 2008). Uma abordagem que aceita como Rorty (2000) argumenta - que não há nenhuma diferença substantiva entre um cientista tentando contribuir para a resolução de uma determinada questão e um chef de cozinha procurando acertar uma receita, ou um cirurgião esforçando-se para operar um joelho ou, ainda, um encanador buscando consertar um fluxo de água. Todos buscam fazer sua parte, dar o melhor de si e, ainda, preocupam-se em explicar para os outros como e onde chegaram. Há questões, sem dúvida, que são mais próximas de nossas competências de base e existem outras das quais o que podemos esperar é contribuir para uma conversa coletiva mais ampla com outros cientistas sociais, com historiadores, fotógrafos, poetas, escritores e documentaristas.

Uma metáfora que poderia ser útil é a da colcha de retalhos. As colchas de retalhos, na tradição original da Nova Inglaterra e dos assentamentos pioneiros, eram sempre produtos coletivos. As pessoas, em especial as mulheres, juntavam-se com o que havia sobrado de tecidos para cortar, bordar, conversar e produzir roupas de cama essenciais para lidar com o frio do inverno. Tornou-se uma expressão negativa na língua portuguesa, uma vez que transmite a ideia de algo mal articulado. Porém, ao lidar com situações nas quais há mais questões que conclusões, em que se verifica a impossibilidade de criar experimentos controlados ou até de aplicar questionários padronizados, o que temos em mãos são retalhos. Pedaços de casos,

4 Ver, por exemplo, Linares (2002), um excelente trabalho empírico sobre o comércio ambulante em Lima, Peru. 
fragmentos de dúvidas, alguns sucessos parciais e alguns fracassos parciais. Ideias práticas que, até certo ponto, funcionaram, mas se detiveram ao encontrar bloqueios e portas fechadas.

Recuperar a versão positiva e coletiva da construção da colcha também permite reconhecer que não há "uma única colcha" a ser bordada, porque nunca haverá uma história verdadeira; sempre haverá histórias possíveis. O importante é a produção coletiva buscando os encaixes entre um retalho e outro; um quebra-cabeça sem desenho a priori cujo desenho final será um entre outros possíveis; produto do consenso da coletividade participante. Neste texto, utilizando essa metáfora metodológica, oferecemos alguns retalhos parcialmente costurados e outros ainda sem encaixe. O convite é coletivo.

\section{O que é a nanoeconomia?}

Em sua pesquisa de campo para a dissertação de mestrado, Neiza Baptista (2005) passou diversas noites nas filas de espera que se localizam do lado de fora dos centros de emprego em São Paulo. Numa dessas noites, conversando com uma jovem, surpreendeu-se quando esta, de repente, começou a chorar e pôs-se a contar a respeito das dificuldades que tivera de enfrentar até chegar àquele local. Morava bem distante e precisava pegar ônibus para alcançar o centro de emprego. No entanto, não tinha dinheiro suficiente, pois precisaria de pelo menos seis passagens: uma de ida e volta para casa e outras tantas, caso houvesse oportunidades de emprego. Pediu emprestado um pouco de farinha, leite, ovos e açúcar, confeccionou diversos bolos, que vendeu fatiado em pontos de ônibus e lugares similares, juntou o dinheiro para pagar as passagens e devolver os ingredientes emprestados. ${ }^{5}$

No Brasil, há estimativas de que mais de 35 milhões de pessoas não conseguem acessar os sistemas precários de transporte público por falta de recursos financeiros. Nesse contexto, o exemplo da jovem é a própria definição da nanoeconomia ${ }^{6}$ : a batalha cotidiana para criar possibilidades, o dia a dia dos microeventos da economia popular, a solidariedade que vem do reconhecimento da situação do outro.

Independente de sua aparência, a nanoeconomia está longe de ser uma noção abstrata. É um produto social cujas possibilidades expressam-se em materialidades e socialidades; uma intersecção sociotécnica em constante negociação (Latour, 2005; Law \& Mol, 1995, Spink, 2003b). Empreendimentos caseiros são uma parte da nanoeconomia, pois se utiliza o pouco espaço disponível no lar para gerar produtos ou vender produtos e serviços. A mini-loja na esquina que vende os produtos necessários para o dia-a-dia para pessoas que não têm espaço para guardar ou que não têm geladeira; a loja improvisada na garagem ou na porta de entrada da casa que vende roupas de segunda mão; serviços de reparos e de consertos de roupas e de equipamentos. Todos frequentemente sem alvará, sem registro, mas construindo possibilidades econômicas de sobrevivência a partir de sua utilidade no micro lugar, no quarteirão, na comunidade. Tipple, Coulson e Kellet (2002), nas conclusões de seu estudo sobre os empreendimentos caseiros (home based enterprises - HBEs) na Bolívia, na Índia, na Indonésia e na África do Sul, comentam que os empreendimentos caseiros não são valorizados nem aparecem nos números das economias nacionais, isto é, sua contribuição para a vida diária é ignorada. São invisíveis estatisticamente e ignorados pelos formuladores de políticas públicas que sonham com o modelo utópico da vida suburbana. O Brasil, por exemplo, é um país onde muito se fala em microcrédito, entretanto, é estimado que somente $2 \%$ da demanda é atendida

5 O exemplo também demonstra a importância de políticas públicas mais equitativas na área de transporte público.

6 A criação e o uso da expressão "nanoeconomia” não tem a pretensão de elaborar uma teoria econômica. Sua função é chamar a atenção para os eventos cotidianos e para as maneiras de sobreviver e de garantir o sustentação familiar. 
em contraste os mais de $110 \%$ da demanda na Bolívia e os $40 \%$ no Chile (Monzoni Neto, 2006).

Sem uma melhor compreensão dos processos sociais presentes na nanoeconomia e da sua capacidade de sobrevivência, não teremos como, de maneira adequada, contribuir para a formulação de políticas públicas que ofereçam possibilidades reais de desenvolvimento local e de construção de alternativas. A nanoeconomia é fruto de negociações constantes, algumas amigáveis e coletivas, outras muito ao contrário, como sua própria invisibilidade demonstra. Uma atividade comercial de porta de casa parece algo simples até ser analisada construtivamente. Como ela foi produzida? Do que depende? Dentro de qual micro cadeia de atividades está inserida? Quais as materialidades e socialidades presentes? Quais são as transações psicossociais do cotidiano que a formam e a sustentam?

Podemos ilustrar esse processo de negociação e de construção constantes tomando por base uma observação feita no centro da zona urbana de Abreu e Lima, um município pernambucano. É um exemplo que se repete em muitos lugares:

Onze horas, domingo de manhã, e as ruas do centro por onde passa o caminho para Igarassu são repletas de atividades. As lojas estão abertas e as calçadas cheias de pessoas fazendo compras. Nas calçadas e na beira da rua asfaltada há também pessoas vendendo seus produtos, ora beneficiados, ora in natura. Suas "lojas portáteis" são carrinhos de pedreiro, fáceis de manobrar, de levar e trazer, com um banquinho de plástico para sentar ao lado. São produtos de sítio, de horta; aquilo que está disponível no dia, que está pronto. Um pouco mais adiante, um senhor vende frango assado para o almoço de domingo; um cenário igual às rotisserias elétricas nas portas das padarias (conhecidas como televisão de cachorro), só que feitas numa churrascaria portátil aberta, similar a um carrinho de pipoca com os frangos espetados ao ar livre. Outro, com uma picape velha, vendendo seus produtos a partir da caçamba, parte in natura e parte processada (geleias, pimentas etc.). Fazem-se compras em ambos os lados da calçada: na parte interna, com as lojas de porta de aço abertas para a rua e, na parte externa, à beira rua, com as lojas portáteis ao ar livre (notas do autor).

A construção do domingo de manhã em Abreu e Lima é fruto de processos os mais variados. Por conveniência, podem-se distinguir elementos materiais, sociais e institucionais, mas, como bem argumentaram Law e Mol (1995), as materialidades e as socialidades são produtos de si mesmas e de suas interconexões. De um lado, temos a construção do lugar (Lefebvre, 1991; Santos, 1996; Spink, 2001), uma materialidade de espaço que é ampla o suficiente para que as pessoas possam vender na calçada ou na beirada da rua. Há também socialidades vinculadas à disposição de motoristas em aceitar uma diminuição do espaço de tráfego como parte de um bem coletivo, como também o senso coletivo da confiança em comprar produtos de pessoas vendendo na rua. Quer dizer, a noção de que é um bom produto, um produto de qualidade, porque é feito em casa ou tirado da horta, que vale o preço e cujo vendedor é confiável. Não se compra tudo nas lojas portáteis. Por exemplo, os remédios genéricos compram-se na farmácia de Senhor Fulano, mas as ervas medicinais compram-se na banca da Dona Cicrana. Há também institucionalidades presentes, que aceitam, confirmam e negociam a calçada - pelo menos no domingo de manhã - como um espaço público que pode ser utilizado por atividades honestas e não registradas de geração de renda.

Por outro lado, o lugar forma-se a partir de sua ocupação, que tem as suas materialidades, socialidades e institucionalidades: o carrinho de pedreiro, a rotisseria portátil, o carvão, os banquinhos de plástico, os produtos para vender, a disposição de pessoas para gastar seu tempo em uma atividade comercial e a disposição social de negociar essa atividade como válida e digna. Aqui também estão presentes as institucionalidades culturais, historicamente enraizadas, resultado de múltiplas negociações sobre a prática da feira como atividade válida (Sato, 2007). 
O resultado é uma rede de fragmentos interconectando-se e produzindo-se mutuamente, construindo espaços econômicos com todas a suas contradições (Vieira \& Vieira, 2003). São actantes (para usar a expressão de Latour) materiais e sociais; são materialidades e socialidades. No trabalho de Adriana Salvitti, Lygia Viégas, Samir Mortada e Daniela Tavares (1999) sobre camelôs na cidade de São Paulo, esses múltiplos fragmentos vão constituindo, ao longo do tempo, o que chamaram de "empresa rua", um sistema extra-oficial que inclui as atividades, sua distribuição e os acordos velados entre fiscais, camelôs e lojistas:

Fora do sistema oficial de ocupação da rua e dentro do sistema informal, encontramos uma organização "formal" entre os camelôs, que vai desde a possibilidade de estabelecimento do ambulante na rua, até o modo de utilização desse espaço e as diversas relações que daí surgem. Esse sistema de regras tácitas vai sendo construído e aprendido no convívio com os outros camelôs que trabalham na mesma zona ou área. Quanto à forma de inserção na rua, percebemos que esta se dá por várias vias: compra de um ponto, pedido para trabalhar em um local e ter a permissão dos lojistas em frente ou dos camelôs ao lado, ocupação de um ponto de um amigo ou parente ou mesmo a ocupação de um espaço onde até então não havia camelôs ao redor (o que pode se dar também em locais onde outros camelôs foram previamente retirados pela prefeitura). Nos lugares onde a concentração de camelôs é bastante alta e que já são ocupados há muitos anos, geralmente a ocupação depende da compra do chamado "ponto". Esse local "pertenceria", pelo tempo de ocupação, a um camelô mais antigo que, portanto, pôde registrá-lo em seu nome, na época em que estes registros eram feitos e válidos oficialmente. Muitos pontos são vendidos ou alugados para outros camelôs. Quanto à organização e utilização do espaço, bem como quanto às relações que aí se estabelecem, um dos depoentes nos conta que aquele que desrespeita os colegas ou os lojistas é denunciado por eles mesmos à prefeitura. Diz, ainda, que se deve ter uma relação amistosa e de confiança com os colegas de trabalho, já que precisam constantemente contar uns com os outros, para que cuidem de sua barraca, possibilitando, por exemplo, que ele vá almoçar, vá ao banheiro ou faça um telefonema ( p. 11).

Entretanto, independentemente de toda sua riqueza, as materialidades, socialidades e institucionalidades que formam o arranjo do domingo em Abreu e Lima, produto e produtores de redes extensas de relações e de expectativas são - como em qualquer rede - tão fortes quanto seu elo mais fraco.

Em São Paulo, na Rua Itapeva, um quarteirão da Avenida Paulista na altura do Museu de Arte Moderna (MASP) e ao lado de um dos primeiros CAPS experimentais no país, havia uma praça de alimentação informal ao ar livre. "Dogueiros" com seus carros convertidos, uma senhora que fazia comida caseira, outra que fazia tapioca e também os inevitáveis vendedores de bijuterias, relógios e capas de telefone celular. Era igual às praças de alimentação nos "shoppings" da cidade e era frequentado pelos trabalhadores dos escritórios dos grandes bancos instalados no mesmo quarteirão e também pelas pessoas indo aos ou saindo dos consultórios médicos da Rua Itapeva. Pessoas sentavam em banquinhos na calçada para comer e conversar, fugindo do ar condicionado e das baias supervisionadas dos escritórios "abertos". Um dia, a subprefeitura "limpou" a rua como parte de suas operações contra o comércio informal e a favor da valorização da Avenida Paulista. Ninguém falou nada e ninguém perguntou para os usuários; presumia-se que era natural que o estado local determinasse o uso do espaço público (notas do autor). 


\title{
Recuperando a psicologia ecológica?
}

\begin{abstract}
A questão "por que as pessoas comem o que comem" é complexa e envolva dimensões culturais e psicológicas (tais como comidas tradicionais e preferências individuais causadas por experiências na infância), como também problemas de transporte, de disponibilidade de comida em uma determinada área e considerações econômicas. Portanto, o primeiro passo para uma análise científica é o tratamento do problema de onde e como os aspectos psicológicos e não psicológicos entrecruzam-se. A resposta vem em parte de uma "teoria de canais". De grande importância nessa teoria é o fato que uma vez que a comida está na mesa, seria comida por alguém na família. A resposta principal à pergunta "por que as pessoas comem o que comem" virá da resposta à pergunta "como a comida chega na mesa e por que?" (Lewin, 1952, pp. 174-175). ${ }^{8}$
\end{abstract}

Com esse exemplo, Lewin abre uma discussão importante sobre a construção de eventos e sobre os múltiplos canais presentes no cotidiano, sobre as portas que abrem e fecham, sobre as possibilidades presentes e sobre os porteiros individuais e coletivos (gatekeepers). Podemos retornar às observações feitas em Abreu e Lima e fazer uma pergunta similar: "como o mercado acontece?". Para responder, teríamos de reconhecer a presença de diversos canais construídos por pessoas, culturas, objetos, leis, regulamentos, práticas comerciais e de consumo, sistemas de transporte, as características físicas dos lugares, entre outros. Em todos esses e em diversos momentos, pessoas, agrupamentos, comunidades, organizações, frentes e redes avocatórias, agências públicas e privadas podem intervir e, de fato, intervêm, abrindo e fechando portas para abrir e fechar opções e acessos, permitindo que certos fluxos continuem e fazendo com que outros parem. Micro cadeias produtivas são também canais de atividades e eventos, ações de porteiros que abrem ou fecham oportunidades dentro do fluxo do cotidiano este é o terreno do qual fazemos parte como também as pessoas entrevistadas no estudo de Salvitti et al. (1999).

Ao discutir as aplicações mais amplas de seu estudo sobre os hábitos alimentares, Lewin enfatizou a importância da identificação das gate sections (seção ou área do canal onde a porta está presente $)^{9}$ nos diferentes canais, tanto sociais quanto físicos e econômicos, que compõem a situação em foco. Compreender a função da "porta" implica reconhecer os diferentes fatores que determinam as decisões dos porteiros. Mudar as práticas dos porteiros e reconstruir a lógica da porta pressupõe intervir na constelação de forças presentes (force field). Para Lewin, a tarefa de identificar os gatekeepers é uma tarefa sociológica, necessária antes de qualquer discussão sobre educação para mudança social.

A abordagem ou teoria dos canais foi elaborada muito antes da formação do campo construcionista, entretanto, nas suas entrelinhas há precursores de uma série de elaborações posteriores. Há também a clara busca de uma intersecção explícita entre o campo da psicologia social e o da sociologia, intersecção essa que hoje reconhecemos a partir da distinção entre a psicologia social psicológica e a psicologia social sociológica (Álvaro \& Garrido, 2007; Farr, 1996). O reconhecimento da importância desse diálogo abre possibilidades de conversas com outros pesquisadores nas ciências sociais como, por exemplo, Norman Long (2001), com sua metodologia de análise de interface, elaborada para focalizar as intersecções entre os diferentes e frequentemente conflitantes campos sociais ou mundos da vida em situações sociais nas quais

7 A professora Arackcy Martins Rodrigues chamou a atenção para a importância deste pequeno texto de dezessete páginas, escrito em 1943, parte da coleção organizada por Cartwright em 1952. A expressão "psicologia ecológica" foi criada por Lewin para chamar a atenção para a justaposição do psicológico e do não psicológico e para a necessidade de ampliar o foco das análises das ações sociais.

8 Tradução do autor.

$9 \mathrm{Em}$ termos de imagem, pode-se entender um gate section como se fosse uma reclusa em um rio. Sem a reclusa, não se passa de um nível do rio para o outro e as materialidades e as socialidades da reclusa são múltiplas: conceitos de engenharia, mecânica hidráulica, pessoas, barcos de tamanho adequado, regras de passagem, tarifas etc. 
há uma busca para construir pontes e acomodar diferenças ou, ao contrário, segregar ou separar posições diferentes.

O debate sobre negociação foi central em muitos dos estudos de Anselm Strauss (1978), a exemplo de seu trabalho clássico sobre o hospital como ordem negociada. Nesse e em outros autores da sociologia do cotidiano, encontraremos pontos de intersecção com as ideias dos pesquisadores da teoria do ator rede (Law \& Hassard, 1999) sobre as redes de relações que envolvem humanos e não-humanos, sobre as negociações que acontecem nas interfaces entre modos de sobrevivência, modos de vida. Com base em seus estudos no Peru, Long (2001) escolheu a expressão livelihood ${ }^{10}$ (sustentação econômica) como foco para a vida econômica.

Estudar a maneira como as pessoas se sustentam requer a identificação das unidades sociais e campos de atividade relevantes; não se deve prejulgar a questão, como fazem muitos estudos, utilizando os pontos convencionais de análise da vida econômica tais como "o lar", "a comunidade local", "o setor produtivo" ou "a cadeia de comodities". Em muitas situações, confederações de lares e redes pessoais amplas englobando uma variedade de atividades e contextos rurais e urbanos diferentes, como também fronteiras nacionais, constituem o tecido social dentro do qual o processo de sustentação e os fluxos de comodities apoiam-se (p. 54). ${ }^{11}$

\section{Dúvidas e alertas}

A discussão iniciada por Kurt Lewin e seus colegas, há 65 anos atrás, sobre a importância da identificação sociológica da dinâmica das portas antes de presumir que uma determinada ação psicológica fosse necessária, tem uma relevância adicional hoje, quando analisamos a produção recente no campo das inserções econômicas alternativas; especialmente em relação às incubadoras e em outras ações na economia solidária, na qual uma das linhas fortes de ação sustenta-se na construção de cooperativas autogestionárias. A aparente redundância da expressão - porque as cooperativas foram sempre organizações coletivas - vem da presença, no Brasil, de empresas intermediadoras de mão-de-obra ou de processos de terceirização, que utilizam a legislação brasileira sobre cooperativas, mas nada têm de parentesco com o movimento cooperativista europeu do século XIX. Cria-se uma distinção vista como importante por diversos autores no campo, entre cooperativas de passagem e cooperativas de convicção.

Estruturas legais que formam suporte para atividades organizadas estarão sempre abertas para usos múltiplos. Tal como as "coopergatos", há pessoas que têm "suas ONGs", igrejas de fachada e sindicatos criados para usufruir do imposto sindical. No caso das cooperativas e da economia solidária, entretanto, a discussão e a preocupação têm outros contornos. Não se trata simplesmente de uma questão de uso ou abuso de um arcabouço legal. ${ }^{12}$ Ao contrário, a associação de um conceito formal-legal (cooperativa) com uma prática organizativa (autogestão) virou a base de uma tese de inserção econômica diferente, que tem consequências na maneira como os microempreendimentos são apoiados, nas ideias que são discutidas, nas práticas de capacitação enfatizadas, no acesso a fundos e apoios públicos e nos nomes que são dados aos empreendimentos, dentre outros. Ou seja, em termos da teoria de canais, trata-se da construção de um caminho para facilitar o acesso aos mercados locais e para

\footnotetext{
10 Em inglês, livelihood refere-se à maneira como as pessoas se sustentam: manutenção e sustentação da vida, a maneira de manter a vida (incluindo renda, comida, patrimônio etc.).

11 Tradução do autor.
}

12 Fernandes Júnior (2007) discute os problemas bastante sérios criados pela legislação cooperativa atual e proposta. 
gerar renda, onde certas ideias, conceitos e práticas são vistos como chaves para abrir possibilidades e realizar o potencial que existe.

Como Oliveira (2007) bem apontou, não há dúvida de que a experiência cotidiana da prática organizativa nas cooperativas orientadas pela economia solidária é diferente daquela presente nas cooperativas de intermediação de mão-de-obra. Não é essa a questão em discussão. Entretanto, também não se questiona que o campo do "cooperativismo" é em nada consensual, conforme demonstrou Roberto Ide (2006) ao estudar os diferentes sentidos em circulação no país, desde as diferentes leituras de origem marxista às referências ao socialismo utópico e às diferentes versões gerencialistas.

A nossa preocupação é que as diferentes proposições em circulação sobre cooperativismo e os argumentos sobre o que é necessário para ter-se uma cooperativa autêntica, ou sobre a importância da autogestão do microempreendimento coletivo, criem nas pessoas, para quem a sustentação econômica é uma questão extremamente prática e imediata, certo estranhamento. É comum encontrar na programação das incubadoras cursos de formação sobre autogestão e cooperativismo e sobre a história da economia solidária buscando, com toda sinceridade, oferecer um horizonte mais amplo para a discussão das pequenas ações de sobrevivência. Infelizmente, conforme relataram Nóbrega (2006) e Zazula (2007), dentre outros, tais informações e proposições nem sempre são compreendidas. São frequentes os relatos das dificuldades que os envolvidos tiveram para fazer sentido a essa "discussão toda" ou até para entender sua relevância.

A esse respeito, Scopinho (2007) traz uma contribuição importante ao discutir a diferença entre cooperar e cooperativismo, com base em seus estudos acerca dos assentamentos do MST e dos documentos que circulam entre atores-chave do movimento. Ao comentar o complexo e contraditório universo de sentidos atribuídos pelos assentados em relação à cooperação e às cooperativas, ela comenta que "cooperar" é visto socialmente como imprescindível para a sobrevivência. $\mathrm{O}$ associativismo formal, por outro lado, reconhecido como uma condição institucional de legalização estatal, é visto como uma necessidade legal. Entre a ação social articulada, incluindo a cooperação espontânea (enquanto valor presente na zona rural), e modelos específicos de estrutura organizacional (a cooperativa), há toda uma gama de posicionamentos ideológicos possíveis sobre mudança social e sobre as possibilidades de ações na infraestrutura determinarem mudanças na superestrutura.

A importância de atentar para a contribuição do estudo das práticas discursivas nessa área é reconhecer quais são os termos organizativos que fazem parte do dia-a-dia. Évora (1996) - em seu estudo sobre cooperativas de Cabo Verde, após a independência, em um período dominado intelectualmente pelas ideias pós-marxistas de Amilcar Cabral (McCulloch, 1983) apontou os processos a partir dos quais um saber novo em circulação (sobre a importância do cooperativismo) foi sendo incorporado e ancorado em saberes autóctones anteriores. Diferentemente de alguém que cresceu a dez milhas de Rochdale, Inglaterra, e para quem o dia-a-dia era do Coop $p^{13}$ - em lojas, prédios e orquestras de metais -, a expressão cooperativa é uma estranha no ninho para uma parte significativa do Brasil. Outras expressões como "comunidade" e "associação" são muito mais comuns e tendem a ser mais usadas quando partem de movimentos sociais, tanto rurais, quanto urbanos. Cooperar, mutirão, associar são palavras de ação que valorizam a processualidade da ação em movimento ${ }^{14}$. "Associação" - por nenhuma razão, a não ser familiaridade - parece ser frequentemente a palavra escolhida, quando algum grau de formalidade é necessário e, não sem razão, uma proporção significativa de organizações de catadores é reconhecida como associação, como também são consideradas associações as organizações de agricultores familiares.

13 A pronúncia em inglês britânico é Co-op.

14 Aliás, a língua portuguesa é rica em palavras organizativas oriundas de fontes diversas (mutirão é de origem tupi-guarani). 
Importante aqui é a análise de Scopinho (2007) sobre as armadilhas das exigências organizativas no campo da reforma agrária, que levam a situações em que a cooperação reduzse a uma política de criação de cooperativas, mesmo com formas de confederação alternativas: ${ }^{15}$

Mesmo concebendo a cooperativa como uma ferramenta de luta política e social, ocorre que, na prática, ela é culturalmente tida como meio de organizar exclusivamente a atividade econômica e, no dia-a-dia, esta sua dimensão prevalece e até se sobrepõe à dimensão político-organizativo. Ou seja, a experiência mostrou que a criação de cooperativas, em si, não organiza politicamente os assentamentos. Ao contrário, as exigências legais e administrativas advindas da institucionalização da cooperação podem acarretar uma carga burocrática intensa e consumir grande parte do tempo dos dirigentes que, depois de alguns anos, não conseguem visualizar mais do que os problemas do cotidiano (p. 90).

No caso do MST, a autora ressalta que o cooperativismo, como modelo organizativo, começou a perder lugar para uma preocupação mais acentuada com a cooperação enquanto prática social que "contribui para organizar o trabalho e a vida cotidiana resgatando valores, tradições e práticas mutualistas, até por força das inúmeras necessidades enfrentadas no cotidiano" (Scopinho, 2007, p. 90).

O problema, expresso em termos da teoria de canais, é que, ao preocuparmo-nos com aquilo que acontece "dentro" da organização ou com a organização "correta", acabamos, primeiro, reificando a organização e dando valor até exagerado à sua especificidade (Spink, 1996). Em seguida, esquecemo-nos dos demais aspectos dos canais que ajudaram ou não a sustentabilidade da iniciativa, por exemplo, o acesso aos mercados, a luta para políticas públicas mais adequadas, dentre outras.

Sem dúvida, os processos de articulação da ação e a busca da sua legitimidade formam parte de uma porta cuja abertura permite acesso a outros patamares e possibilidades. Entretanto, corremos o risco de transformar essa porta em um labirinto semântico em que as pessoas se perdem nas disputas entre porteiros que se consideram, cada um, o legítimo guardião da porta. Trata-se de um labirinto no qual os recursos próprios, oriundos dos cotidianos da ação (os termos em uso), são desvalorizados diante de uma terminologia dita oficial (com as implicações de sempre em termos de acesso a fundos e apoios).

\section{Conclusões extremamente parciais}

Um entre diversos apontamentos possíveis que poderia servir como ponto de partida na costura coletiva é aquele que Salvitti et al. (1999) referem ao comentar a permanência no degrau inferior:

A inserção no mercado formal frequentemente aparece como possibilidade mais viável dentro do próprio setor terciário. Entre os entrevistados, muitos desejavam ter um negócio próprio - uma pequena loja, um lava rápido, um barzinho etc. O obstáculo mais apontado para atingir tal objetivo foi a falta de recursos para o investimento inicial. Sem capital suficiente para pagar o aluguel comercial de uma loja, os camelôs permanecem nessa espécie de "degrau inferior" do setor terciário em que podem vender suas mercadorias com menos despesas. É o caso de Elizabeth, 31 anos, paulistana que vende relógios. Ela teve de abrir mão do seu plano de ter uma loja em um pequeno shopping e trabalhar como ambulante (p. 9). 
Nos trabalhos de acompanhamento de iniciativas econômicas alternativas no Centro de Estudos de Administração Pública e Governo da FGV-SP, a questão dos degraus de acesso é sempre um fator muito presente. Mesmo em exemplos de sucesso, como da APAEB ${ }^{16}$ (Almeida, 2000) - na zona do sisal da Bahia - ou da ASMARE $^{17}$ (Jacobi, 2000) - atuante na área de reciclagem urbana em Belo Horizonte -, as lutas são longas. A APAEB levou mais de 25 anos para receber um mínimo de apoio do governo estadual (mesmo sendo o mais importante empregador da região) e a fábrica de beneficiamento de plástico para reciclagem, que a ASMARE tanto queria, ainda está em fase de instalação, 18 anos após ter sido fundada a associação. Os esforços necessários para ingressar ou atingir um patamar mínimo de melhoria econômica são imensos e, sem a intervenção direta do Estado para abrir portas e limpar os bloqueios nos canais, são quase impossíveis, conforme demonstrou o programa de verticalização da produção agrícola (Prove) do Governo do Distrito Federal na gestão de Cristovam Buarque (Miyashita, 1998).

De experiência em experiência, temos encontrado agências estatais de apoio aos micro negócios tendo dificuldades com a nanoeconomia, mesmo reconhecendo que os microempreendimentos de rua ou de base caseira são atividades decentes e dignas, preferindo trabalhar com empreendimentos um pouco mais consolidados (leia-se: que já conseguiram passar algumas das portas ou reclusas nos canais econômicos, que já conseguiram subir alguns degraus, que se adéquam mais ao imaginário da pequena e microempresa). Por outro lado, sabemos que o microcrédito produtivo, sem efetiva socialização, apoio e acompanhamento, tende a gerar poucos resultados. Não se trata de "capacitação", mas de algo bastante singelo e humano: ter companhia e ter com quem conversar, compartilhar e ter confirmada a dignidade social da atividade.

Na Nicarágua, na década de 1990, um programa de desenvolvimento local juntou três eixos de ação em bairros populares com grande impacto. $O$ primeiro eixo era de pequenos projetos de melhoria de infraestrutura, discutidos e decididos pelas comunidades e pelos governos locais, construídos em cogestão com financiamento dividido entre agências internacionais, governos locais e comunidades (neste caso, com a doação de mão-de-obra). O segundo eixo foi o fornecimento de microcrédito produtivo para os micro e nanoempreendimentos na mesma localidade (um ou dois quarteirões), também com as prioridades discutidas pela comunidade. $\mathrm{O}$ terceiro eixo foi de empréstimos individuais com aval solidário para os moradores melhorarem suas casas. Em quatro anos, o PRODEL (Programa de Desarrollo Local) estimulou 260 projetos de melhorias em 155 bairros populares, forneceu mais de 4.000 empréstimos para melhorias de habitação e quase 12.500 empréstimos de microcrédito para 2.400 empreendimentos (Stein, 2001). Ao todo, foram mais de $38 \mathrm{mil}$ famílias beneficiadas com um investimento coletivo equivalente a 900 reais por família, levando-se em conta que o fundo de financiamento já tinha tornado-se auto-sustentável. A diferença talvez esteja na coletivização dentro dos horizontes do lugar em vez da individualização mais comum na prática brasileira. Dois ou três quarteirões são uma coletividade, uma confederação de famílias dentro da qual é possível discutir a sustentação econômica e coletivizar a discussão sobre dignidade e trabalho decente enquanto processos de ação sociotécnica, de construção de novas materialidades e socialidades.

Levar seriamente a discussão sobre seu desenvolvimento, vinculando melhorias coletivas com o estímulo de empreendimentos que são do próprio lugar e com as prioridades individuais para cada lar, talvez se apresente como um caminho a ser considerado. Afinal, as pessoas envolvidas nos empreendimentos solidárias moram onde?

16 Associação de Desenvolvimento Sustentável e Solidário da Região Sisaleira.

17 Associação dos Catadores de Papelão e Material Reaproveitável. 


\section{Referências}

Abramo, H. \& Branco, P. P. M. (Orgs.). (2005). Retratos da juventude brasileira: análises de uma pesquisa nacional. São Paulo: Perseu Abramo.

Almeida, W. (2000). Cidadania ativa: a experiência dos pequenos produtores rurais. In I. Camarotti \& P. K. Spink (Orgs.), Parcerias e pobreza: soluções locais na construção de relações sócio-econômicas. Rio de Janeiro: Fundação Getúlio Vargas.

Álvaro, J. L. \& Garrido, A. (2007). Psicologia social: perspectivas psicológicas e sociológicas. São Paulo: McGraw Hill.

Aued, B. W. (1999). Histórias de profissões em Santa Catarina: ondas largas "civilizadoras". Florianópolis: Editora do Autor.

Antunes, R. (1999). O mundo precarizado do trabalho e seus significados. Cadernos de Psicologia Social do Trabalho. 2, 55-72.

Baptista, N. C. S. (2005). Pegando Fila... contando um pouco da cotidianidade do trabalhador desempregado na cidade de São Paulo. Dissertação de Mestrado, Programa de Estudos Pós-Graduados em Psicologia Social, Pontifícia Universidade Católica de São Paulo, São Paulo.

Castel, R. (1997). As armadilhas da exclusão. In M. Belfiore-Wanderley, L. Bogus \& M. C. Yazbeck (Orgs.), Desigualdade e a questão social. São Paulo: Educ.

CESIT (2006). Informações para a elaboração das estratégias das políticas públicas de emprego, renda e relações de trabalho. Campinas: CESIT/MTE.

Esteves, E. G. (2002). Emprego versus trabalho associado: despotismo e política na atividade humana de trabalho. Cadernos de Psicologia Social do Trabalho, 5, 51-56.

Évora, I. M. A. (1996). As representações sociais da cooperativa: um estudo na Ilha de Santiago, Cabo Verde. Dissertação de Mestrado, Instituto de Psicologia, Universidade de São Paulo, São Paulo.

Farr, R. (1996). The roots of modern social psychology, 1872-1954. Oxford: Blackwell.

Fernandes Júnior, O. (2007). A dura vida da sociedade alternativa. Desafios, 4 (30), 24-29.

IBGE (2004). Síntese de indicadores sociais 2004 (vol. 15). Brasília: IBGE.

Ide, R. (2006). Sobre as possibilidades de efetivação das cooperativas no cotidiano: uma aproximação construcionista. Cadernos de Psicologia Social do Trabalho, 9 (2), 1-13.

IPEA (2006). Brasil, o estado de uma nação: mercado de trabalho, emprego e informalidade. Brasília: IPEA.

IPEA (2008). Brasil, o estado de uma nação: Estado, crescimento e desenvolvimento, a eficiência do setor público no Brasil. Brasília: IPEA.

Jacobi, P. (2000). Asmare: o papel das parcerias na geração de renda. In I. Camarotti \& P. K. Spink (Orgs.), Parcerias e pobreza: soluções locais na construção de relações sócio-econômicas. Rio de Janeiro: Fundação Getúlio Vargas.

Kabeer, N. \& Cook, S. (Eds.). (2008). Economic growth, social protection and "real" labour markets. IDS Bulletin, $39,2$.

Latour, B. (2005). Reassembling the social: an introduction to actor network theory. Oxford: Oxford University Press.

Law, J. \& Hassard, J. (Eds.). (1999). Actor network theory and after. Oxford: Blackwell.

Law, J. \& Mol, A. (1995). Notes on materiality and sociality. The Sociological Review, 43 (2), 274-294.

Lefebvre, H. (1991). The production of space. Oxford: Blackwell.

Lewin, K. (1952). Psychological ecology. In D. Cartwright (Ed.), Field theory in social science: selected theoretical papers by Kurt Lewin. London: Tavistock.

Linares, L. A. (2002). Sumas y restas: el capital social como recurso en la informalidad (las redes de los comerciantes ambulantes de independencia). Lima, Peru: Alternativa.

Long, N. (2001). Development sociology: actor perspectives. London: Routledge. 
McCulloch, J. (1983). In the twilight of revolution: the political theory of Amilcar Cabral. London: Routledge \& Kegan Paul.

Nóbrega, J. da S. (2006). As possibilidades de uma ecologia de saberes: a negociação de sentidos no processo de incubação. Dissertação de Mestrado, Programa de Estudos Pós-Graduados em Psicologia Social, Pontifícia Universidade Católica de São Paulo, São Paulo.

Miyashita, H. (1998). Programa de Verticalização da Pequena Produção Agrícola. In L. M. Fujiwara, N. L. N. Alessio \& M. F. S. Farah (Orgs.), Vinte experiências de Gestão Pública e Cidadania. São Paulo: Programa Gestão Pública e Cidadania.

Monzoni Neto, M. P. (2006). Impacto em renda do micro crédito: uma investigação empírica sobre geração de renda do Crédito Popular Solidário (São Paulo Confia) no município de São Paulo. Tese de Doutorado, Escola de Administração de Empresas de São Paulo, Fundação Getúlio Vargas, São Paulo.

Oliveira, F. (2007). Os sentidos do cooperativismo de trabalho: as cooperativas de mão-de-obra à luz da vivência dos trabalhadores. Psicologia E Sociedade, 19 (número especial), 75-83.

Organização Internacional do Trabalho (2000). Decent work and poverty reduction in the global economy. Second Session of the Preparatory Committee for the Special Session of the General Assembly on the Implementation of the Outcome of he World Summit for Social Development and Further Initiatives.

Organização Internacional do Trabalho (2001). Labour Overview (pp. 45-47). Geneva: International Labour Organisation.

Puplampu, B. B. (2003). The "neglected professions": why don't we study taxi drivers, waiters, farmers, street sweepers and... The Occupational Psychologist, 48, 3-9.

Rorty, R. (2000). The decline of redemptive truth and the rise of a literary culture. Artigo disponível na internet em: http://w.w.w.stanford.edu/ rrorty/decline.htm.

Santos, M. (1996). A natureza do espaço. São Paulo: Hucitec.

Sato, L. (2007). Processos cotidianos de organização do trabalho na feira livre. Psicologia $\mathfrak{G}$ Sociedade, 19 (número especial), 95-102.

Salvitti, A., Viégas, L. de S., Mortada, S. P. \& Tavares, D. S. (1999). O trabalho do camelô: trajetória profissional e cotidiano. Cadernos de Psicologia Social do Trabalho, 2, 1 -23.

Scopinho, R. A. (2007). Sobre cooperação e cooperativas em assentamentos rurais. Psicologia $\mathbb{E}$ Sociedade, 19 (número especial), 84-94

Spink, P. K. (1996). Organização como fenômeno psicossocial: notas para uma redefinição de psicologia do trabalho. Psicologia E⿱乛 Sociedade, 8 (1), 174-192.

Spink, P. K. (2001). O lugar do lugar na análise organizacional. Revista de Administração Contemporânea, 5 (número especial), 11-34.

Spink, P. K. (2003a). Pesquisa de campo em psicologia social: uma perspectiva pós-construcionista. Psicologia $\mathfrak{E}$ Sociedade, 15 (2), 18-42.

Spink, P. K. (2003b). A perda, redescoberta e transformação de uma tradição de trabalho: a teoria sociotécnica nos dias de hoje. Organizações e Sociedade, 10 (28), 117-129.

Spink, P. K. (2007a). Equity and public action: facing the challenge of Brazil's inequality. Harvard Review of Latin America, 6 (3), 33-36.

Spink, P. K. (2007b). Replanteando la investigación de campo: relatos y lugares. Fermentum: Revista Venezolana de Sociologia y Antropologia, 17 (50), 561-574.

Spink, P. K. (2008). O pesquisador conversador no cotidiano. Psicologia E Sociedade, 20 (número especial), 70-77.

Somavia, J. (1999). Decent work. Report by ILO Director-General. 87th session of the International Labour Conference.

Stein, A. (2001). Participation and sustainability in social projects: the experience of the Local Development Programme (PRODEL) in Nicaragua. London: IIED.

Strauss, A. (1978). Negotiations: varieties, contexts, processes and social order. San Francisco: Jossey-Bass.

Tipple, G., Coulson, J. \& Kellet, P. (2002). The effects of home-based enterprises on the residential environment in developing countries. In S. Romaya \& C. Rakodi (Eds.), Building sustainable urban settlements: approaches and case studies in the developing world (pp. 62-76). London: ITDG Publishing. 
Vieira, E. F. \& Vieira, M. M. F. (2003). Espaços econômicos: geoestratégia, poder e gestão do território. Porto Alegre: Sagra Luzzatto.

Zazula, M. (2007). Os sentidos da economia solidária: os caminhos da construção da autonomia coletiva e organizativa. Tese de Doutorado, Programa de Estudos Pós-Graduados em Psicologia Social, Pontifícia Universidade Católica de São Paulo, São Paulo.

\section{Endereço para correspondência}

peter.spink@fgv.br

Recebido em: 02/09/2008

Aprovado em: 04/11/2008 